\title{
Relationship between Body Mass Index, Blood Pressure, and Visual Acuity in Residents of Esan West Local Government Area of Edo State, Nigeria
}

\author{
I. O. Ernest-Nwoke, ${ }^{1}$ M. O. Ozor, ${ }^{1}$ U. Akpamu, ${ }^{1,2}$ and M. O. Oyakhire ${ }^{1}$ \\ ${ }^{1}$ Department of Physiology, Faculty of Basic Medical Sciences, College of Medicine, Ambrose Alli University, \\ Ekpoma PMB 14, Nigeria \\ ${ }^{2}$ Department of Health Promotion and Education, Faculty of Public Health, University of Ibadan, Ibadan, Nigeria
}

Correspondence should be addressed to U. Akpamu; uwaifoha@yahoo.co.uk

Received 28 June 2014; Revised 6 August 2014; Accepted 6 August 2014; Published 19 August 2014

Academic Editor: Gary Lopaschuk

Copyright ( 2014 I. O. Ernest-Nwoke et al. This is an open access article distributed under the Creative Commons Attribution License, which permits unrestricted use, distribution, and reproduction in any medium, provided the original work is properly cited.

\begin{abstract}
Aim. To study the relationship between body mass index (BMI) and blood pressure (BP) on visual acuity among apparently healthy residents of Ekpoma, Esan West Local Government Area of Edo State, Nigeria. Methodology. This is a cross-sectional descriptive study among 225 subjects (ages of 18-35 years) from whom BP, body weight, and height were collected. Visual acuity was measured using the Snellen chart following standard procedures of number of letters seen at 6-metre distance. The data were then analyzed using SPSS version 17. Results. The sampled population consists of 112 male and 113 female (mean age $31.72 \pm 14.2$ years). Majority (180) of the respondents had normal visual acuity. However, compared with the respondents with normal BMI $(R 19.61 \pm 1.5$; $L 19.67 \pm 1.70)$, visual acuity of underweight $(R 18.53 \pm 2.30 ; L 18.53 \pm 2.70)$ and obese $(R 15.68 \pm 4.79 ; L 17.73 \pm 1.70)$ were more deviated. Similarly, compared with respondent with normal BP $(120-125 / 80-85 \mathrm{mmHg} ; R 18.00 \pm 2.53 ; L 18.07 \pm 3.11)$, hypotensive $(R 15.5 \pm 7.35 ; L 15.00 \pm 10.20)$, and hypertensive $(R 15.01 \pm 21.25 ; L 15.00 \pm 11.91)$ respondents had deviated visual acuity. Conclusion. Abnormal body weight (underweight and obese) and BP (hypotension and hypertension) have potential negative impacts on visual acuity. Based on the observed relationship between weights, BP, and visual acuity, eye examinations can be included as regular screening exercise for abnormal BMI and BP conditions.
\end{abstract}

\section{Background}

Obesity is a major public health problem with prevalence increasing at overwhelming rates [1-4]. It is implicated as a risk factor for several systemic diseases such as coronary heart disease [5], type 2 diabetes mellitus [6], hypertension, stroke, dyslipidemia, osteoarthritis, and sleep apnea $[3,7,8]$.

Similarly, the global prevalence of hypertension is on the increase. In fact, a recent community based study of rural and semiurban population puts the prevalence of hypertension in Nigeria at $32.8 \%$ [9]. It is associated with serious endorgan damage such as heart disease, stroke, renal disease, and blindness [10-12], which can be prevented by adequate blood pressure control $[13,14]$.
Obesity has been reported to affect visual acuity negatively [15] but the ocular conditions underlying this association and the potential implications are unclear. Similarly, hypertension has been reported as a cause of blurred and altered vision [16-18]. In fact, in preeclampsia, a hypertensive emergency, vision loss is one serious complication according to O'Brien et al. [19] and Gibson [20].

According to several studies, visual impairment adds to the burden of several microvascular and macrovascular complications in people with diabetes and compromises quality of life [21-25]. Worrisome is the fact that limited study has been carried out to investigate the influence body weights and blood pressures have on visual functioning such as visual acuity. Hence, this study was undertaken to investigate 
the effect of obesity and hypertension, indicated by BMI and blood pressure, respectively, on visual acuity.

\section{Materials and Methods}

Study Area. The study was conducted in Ekpoma, Esan West Local Government Area of Edo State, Nigeria. The area lies between latitude $6040^{\circ} \mathrm{N} 6045^{\circ} \mathrm{N}$ and longitude $6005^{\circ} \mathrm{E} 60$ $10^{\circ} \mathrm{E}[26]$.

Targeted Population. The target population consists of 225 subjects who were between the ages of 18 and 35 years.

Inclusion Criteria. Subjects with no history of eye problems (visual pathology) and or head trauma and normal eye health were included in this study.

Exclusion Criteria. Subjects who use glasses, are above the age of 35 years, and have a history of visual impairment, as well as those who are on medication due to illness were excluded for this study.

Ethical Consideration. Before enrolment into the study, informed consent was obtained. The principle of the declaration of Helsinki on the right of the subject was employed.

Study Duration. The study was conducted between June and September, 2013.

Method of Data Collection. Data was obtained using direct interview and a pretested questionnaire, which was translated into the local language. Where the respondent is not fluent in English, the translated version was administered with the help of Esan speaking interpreters.

The questionnaire used was designed to elicit information on sociodemographics, as well as blood pressure, weight, and height measurement and visual acuity was determined using standard laboratory procedures.

Sample Collection and Analysis. Blood pressure was measured using automated arm blood pressure meter (Germany). The measurement was performed three times at an interval of 10 minutes and the average recorded.

Weight $(\mathrm{Kg})$ was measured using the simple bathroom weighting scale (China). This was also performed three times and the average was recorded.

Height $(\mathrm{cm})$ was measured using tape rule (Nigeria). The value was then converted to meter.

Body mass index was accessed by calculation using the values obtained for weight $(\mathrm{Kg})$ and height $(\mathrm{m})$. Values less than $19.99 \mathrm{Kg} / \mathrm{M}^{2}$ were classified as underweight; 20.0 to $24.99 \mathrm{Kg} / \mathrm{M}^{2}$ as normal weight; 25 to $29.99 \mathrm{Kg} / \mathrm{M}^{2}$ as overweight; and greater than $30 \mathrm{Kg} / \mathrm{M}^{2}$ as obese [27].

The visual acuity was tested in each eye separately, in line with Smith and Maure [28], Darling and Thorpe [29], and Garland's [30] recommendation. This was measured with a Snellen chart showing letters. Respondents were tested at standard distances of six metres. The Snellen chart was hung
TABLE 1: Prevalence of visual acuity in the studied population.

\begin{tabular}{lcc}
\hline Visual acuity & Frequency & Percentage (\%) \\
\hline Good & 180 & $80.00 \%$ \\
Fair & 35 & $15.56 \%$ \\
Poor & 10 & $4.44 \%$ \\
\hline Total & 225 & $100.00 \%$ \\
\hline
\end{tabular}

on a wall at a distance of 6 metres in a well-lit room at a height of 2 metres. Visual Acuity was measured one eye at a time (monocularly) with each respondent standing and facing the chart and then reading out the letters on the charts starting from the biggest one to the smallest readable. The eye not being measured was covered with a hand-held occluder held in place by the researcher. The number of letters the respondents were able to see at this distance was recorded.

Data Analysis. Data collected was analyzed for statistics using statistical software package (SPSS version 17). Where applicable, the simple mean and percentages were used while the test for significance was done using the one way analysis of variance.

\section{Results}

The sampled population was made up of 112 males and 113 females with mean age of $31.72 \pm 14.2$ years.

As shown in Table 1 , majority $(180 ; 80.00 \%)$ of the respondents had a good visual acuity while $15.56 \%$ (35) had fair visual acuity and the remaining $4.44 \%$ (10) had poor visual acuity.

On the bases of body weight, respondents with normal weight had very good visual acuity of $19.61 \pm 1.5$ letters in the right eye and $19.67 \pm 1.70$ letters in the left eye. However, respondents that were underweight had a mean visual acuity of $18.53 \pm 2.30$ letters in the right eye and $18.53 \pm 2.70$ in the left eye, while those that were overweight and obese had visual acuity of $15.68 \pm 4.79$ letters in the right eye and $17.73 \pm$ 1.70 in the left eye. For the normal weight and underweight respondents, both eyes were not different in the visual acuity values. However, the overweight and obese respondents had better visual acuity in the left eye.

On the bases of blood pressure, respondents with normal blood pressure (120-125/80-85 $\mathrm{mmHg}$ ) presented a mean visual acuity of $18.00 \pm 2.53$ letters in the right eye and $18.07 \pm$ 3.11 letters in the left eye. While respondent with low blood pressure presented a mean visual acuity of $15.50 \pm 7.35$ letters and $15.00 \pm 10.20$ letters in the right and left eye, respectively, those with high blood pressure presented a mean visual acuity of $15.01 \pm 21.25$ and $15.00 \pm 11.91$ letters in the right and left eye, respectively. Over all, both eyes were not different in their visual acuity values irrespective of blood pressure categories the respondents fall into (Table 3 ).

\section{Discussion}

This study showed that majority of the population within the ages of 18 and 35 years in Esan West Local Government 
Area have good visual acuity. However, the importance of community based vision screening in primary eye care and World Health Organisation (WHO) global initiative tagged vision 2020 "Right to Sight" is very important considering the findings of this study on population with poor visual acuity. In line with this, the World Health Assembly [31] passed a resolution for the elimination of avoidable blindness and urged member states to support the global initiative. There is no doubt that it remains a simple and cost effective means of detecting visual problems which would have gone undetected. This is illustrated in the present study where $20.00 \%$ of the respondents had visual acuities that deviated from the very good visual function and would have never been noted or treated as they had no eye test in mind. By implication, the study indicated that 1 in every 5 persons in Edo State has visual acuity problem. For the respondents with normal body weight and blood pressure, visual acuity was comparable in both eyes and same was observed in the blood pressure classifications and body weight classifications except in the overweight and obese respondents where visual acuity was better in the left eye. Other researchers have also noted no differences in visual acuities in both eyes [32].

Although body weights that deviated from the normal respondents were determinants of a poor visual acuity, overweight and obese respondents had poorer visual acuity than the underweight.

Consonant with the findings of this study, Bergman et al. [15] reported a negative association between obesity and visual acuity. In fact, obesity has been associated with several eye diseases like cataract [33-35], age-related maculopathy $[36,37]$, diabetic retinopathy $[38,39]$, and glaucoma $[40-42]$. Momeni-Moghaddam et al. [43] reported that weights classified as normal or overweight have better binocular performance than those classified as underweight or obese. In dissimilarity with the present study, Momeni-Moghaddam et al. [43] reported the worst binocular performance in underweight subjects as against the overweight and obese in the case of the present study (see Table 2). In line with the present study, Ozor et al. [44] have reported underweight, overweight, and obese subjects to have wider near point of convergence.

Although blood pressures that deviate from the normal affect visual acuity, lower and higher blood pressures affect visual acuity in the same way and in the same degree. In line with the findings of this study, hypertension especially uncontrolled type, has been reported to be associated with serious end-organ damage such as heart disease, stroke, renal disease, and blindness [10-12]. Also, some epidemiological studies have associated cardiovascular disease and glaucoma [45-47] and thus support the findings of this present investigation. A recent study by Ozor et al. [44] has also reported high blood pressure to increase near point of convergence and this correlates with the finding of this study. The present observations on the effect blood pressures have on visual acuity are justified considering the facts that hypertension causes blurred and altered vision [16-18]. Also, preeclampsia, which is a hypertensive emergency, has several serious complications including vision loss $[19,20]$. Our finding on the relationship between hypotension and
TABLE 2: Relationship between body weight and visual acuity.

\begin{tabular}{lcc}
\hline Body weight & Right eye visual acuity & Left eye visual acuity \\
\hline Underweight & $18.53 \pm 2.30^{\mathrm{a}}$ & $18.53 \pm 2.70^{\mathrm{a}}$ \\
Normal weight & $19.61 \pm 1.50^{\mathrm{a}}$ & $19.67 \pm 1.70^{\mathrm{a}}$ \\
Overweight/obese & $15.68 \pm 40^{\mathrm{a}}$ & $17.73 \pm 1.70^{\mathrm{a}}$ \\
\hline
\end{tabular}

Values are mean \pm standard deviation; mean values with different superscripts are significantly different at $P<0.05$.

TABLE 3: Relationship between blood pressure and visual acuity.

\begin{tabular}{lcc}
\hline Blood pressure & $\begin{array}{c}\text { Right eye } \\
\text { visual acuity }\end{array}$ & $\begin{array}{c}\text { Left eye } \\
\text { visual acuity }\end{array}$ \\
\hline $\begin{array}{l}\text { Underweight } \\
\text { (less than } 120-125 / 80-85 \mathrm{mmHg})\end{array}$ & $15.50 \pm 7.35^{\mathrm{a}}$ & $15.00 \pm 10.20^{\mathrm{a}}$ \\
$\begin{array}{l}\text { Normal blood pressure } \\
(120-125 / 80-85 \mathrm{mmHg})\end{array}$ & $18.00 \pm 2.53^{\mathrm{a}}$ & $18.07 \pm 3.11^{\mathrm{a}}$ \\
$\begin{array}{l}\text { Overweight/obese } \\
\text { (greater than } 120-125 / 80-85 \mathrm{mmHg})\end{array}$ & $15.01 \pm 21.25^{\mathrm{a}}$ & $15.00 \pm 11.91^{\mathrm{a}}$ \\
\hline
\end{tabular}

Values are mean \pm standard deviation; mean values with different superscripts are significantly different at $P<0.05$.

hypertension and visual acuity is in place when one considers the facts by Flammer et al. [48] that the vasculature of the eye shares many features with the vasculature of the heart and is often exposed to the same intrinsic and environmental influences and, thus, the eye may indeed be a window to the heart. Indeed, systemic cardiovascular diseases have been associated with structural vascular changes in the retina [48] and hence the finding of this study.

Conclusively, this study revealed that visual functioning indicated by visual acuity is a problem in Esan West Local Government Area of Edo State, Nigeria, and may be so for the country at large. Specifically, abnormal body weight (underweight and obese) and blood pressure (hypotension and hypertension) have potential negative impact on visual acuity. This study therefore showed that there is a relationship between weights, blood pressures, and visual acuity. In fact, hypotension, hypertension, underweight, and overweight/obesity are risk factors for eye diseases as presented by the findings of this study.

Based on the findings of this study, managing and preventing abnormal blood pressures and body weights is a sure practice for ensuring normal visual functioning. Hence, eye examinations can be included as regular screening exercise for conditions of abnormal weights and blood pressures. This therefore, calls for mass visual acuity screening of individuals in the country at large so as to join the World Health Assembly global initiative to elimination avoidable blindness.

\section{Limitations of the Study}

The major limitation of this study is that we measured visual acuity using Snellen charts as a part of routine clinical practice rather than in a standardized research setting or using more sophisticated study charts that would have pointed out other visual pathologies. 


\section{Conflict of Interests}

The authors declare that there is no conflict of interests regarding the publication of this paper.

\section{Acknowledgments}

The authors appreciate the efforts of our research trained assistants that were involved in data collections as well as those who volunteered to participate in this study.

\section{References}

[1] M. J. Friedrich, "Epidemic of obesity expands its spread to developing countries," Journal of the American Medical Association, vol. 287, no. 11, pp. 1382-1386, 2002.

[2] N. Friedman and E. L. Fanning, "Overweight and obesity: an overview of prevalence, clinical impact, and economic impact," Disease Management, vol. 7, supplement 1, pp. S1-S6, 2004.

[3] D. W. Haslam and W. P. T. James, “Obesity," The Lancet, vol. 366, no. 9492, pp. 1197-1209, 2005.

[4] J. O. Hill, V. Catenacci, and H. R. Wyatt, "Obesity: overview of an epidemic," Psychiatric Clinics of North America, vol. 28, no. 1, pp. 1-23, 2005.

[5] R. H. Eckel, R. M. Krauss, and AHA Nutrition Committee, "American Heart Association call to action: obesity as a major risk factor for coronary heart disease," Circulation, vol. 97, no. 21, pp. 2099-2100, 1998.

[6] S. M. Grundy, "Metabolic complications of obesity," Endocrine, vol. 13, no. 2, pp. 155-165, 2000.

[7] V. J. Lawrence and P. G. Kopelman, "Medical consequences of obesity," Clinics in Dermatology, vol. 22, no. 4, pp. 296-302, 2004.

[8] F. X. Pi-Sunyer, "Medical hazards of obesity," Annals of Internal Medicine, vol. 119, no. 7, pp. 655-660, 1993.

[9] I. I. Ulasi, C. K. Ijoma, and O. D. Onodugo, "A communitybased study of hypertension and cardio-metabolic syndrome in semi-urban and rural communities in Nigeria," BMC Health Services Research, vol. 10, article 71, 2010.

[10] M. D. Cressman and R. W. Gifford Jr., "Hypertension and stroke," Journal of the American College of Cardiology, vol. 1, no. 2, pp. 521-527, 1983.

[11] W. S. Post, M. N. Hill, C. R. Dennison, J. L. Weiss, G. Gerstenblith, and R. S. Blumenthal, "High prevalence of target organ damage in young, African American Inner-City men with hypertension," Journal of Clinical Hypertension, vol. 5, no. 1, pp. 24-30, 2003.

[12] S. Khakurel, R. K. Agrawal, and R. Hada, "Pattern of end stage renal disease in a tertiary care center," Journal of the Nepal Medical Association, vol. 48, no. 174, pp. 126-130, 2009.

[13] C. Cuspidi, L. Lonati, L. Sampieri et al., "Prevalence of target organ damage in treated hypertensive patients: different impact of clinic and ambulatory blood pressure control," Journal of Hypertension, vol. 18, no. 6, pp. 803-809, 2000.

[14] B. Neal, S. MacMahon, N. Chapman et al., "Effects of ACE inhibitors, calcium antagonists, and other blood-pressurelowering drugs: results of prospectively designed overviews of randomised trials," The Lancet, vol. 356, no. 9246, pp. 1955-1964, 2000.

[15] B. Bergman, H. Nilsson-Ehle, and J. Sjöstrand, "Ocular changes, risk markers for eye disorders and effects of cataract surgery in elderly people: a study of an urban Swedish population followed from 70 to 97 years of age," Acta Ophthalmologica Scandinavica, vol. 82, no. 2, pp. 166-174, 2004.

[16] E. Rodriguez-Cruz and L. M. Ettinger, Hypertension, eMedicine Pediatrics: Cardiac Disease and Critical Care Medicin, Medscape, 2010.

[17] J. M. Dionne, C. L. Abitbol, and J. T. Flynn, "Hypertension in infancy: diagnosis, management and outcome," Pediatric Nephrology, vol. 27, no. 1, pp. 17-32, 2012.

[18] N. D. Fisher and G. H. Williams, "Hypertensive vascular disease," in Harrison's Principles of Internal Medicine, D. L. Kasper, E. Braunwald, A. S. Fauci et al., Eds., pp. 1463-1481, McGraw-Hill, New York, NY, USA, 16th edition, 2005.

[19] E. O’Brien, D. G. Beevers, and G. Y. H. Lip, ABC of Hypertension, BMJ Books, London, UK, 2007.

[20] P. Gibson, "Hypertension and pregnancy," eMedicine Obstetrics and Gynecology, Medscape, June 2009.

[21] F. E. Hirai, J. M. Tielsch, B. E. K. Klein, and R. Klein, “Tenyear change in vision-related quality of life in type 1 diabetes: wisconsin epidemiologic study of diabetic retinopathy," Ophthalmology, vol. 118, no. 2, pp. 353-358, 2011.

[22] G. C. Jones, J. E. Crews, and M. L. Danielson, "Health risk profile for older adults with blindness: an application of the international classification of functioning, disability, and health framework," Ophthalmic Epidemiology, vol. 17, no. 6, pp. 400410, 2010.

[23] J. Collerton, K. Davies, C. Jagger et al., "Health and disease in 85 year olds: baseline findings from the Newcastle $85+$ cohort study," British Medical Journal, vol. 339, Article ID b4904, 2009.

[24] J. R. Evans, A. E. Fletcher, R. P. L. Wormald et al., "Prevalence of visual impairment in people aged 75 years and older in Britain: results from the MRC trial of assessment and management of older people in the community," British Journal of Ophthalmology, vol. 86, no. 7, pp. 795-800, 2002.

[25] A. J. Sinclair, A. J. Bayer, A. J. Girling, and K. W. Woodhouse, "Older adults, diabetes mellitus and visual acuity: a communitybased case-control study," Age and Ageing, vol. 29, no. 4, pp. 335$339,2000$.

[26] A. O. Obabori, R. Ebosele, and S. K. Mokidi, "Decay problems in cities: renewal options," JABS, vol. 4, no. 1-2, pp. 144-153, 2006.

[27] WHO, "Obesity preventive and managing the global epidemiology," Report of a WHO Consultation on Obesity, Geneva, Switzerland, 1998.

[28] M. C. Smith and F. A. Maure, Community Health Nursing Theory Practices, Elsevier Saunders, Philadelphia, Pa, USA, 1995.

[29] V. Darling and M. Thorpe, Ophthalmic Nursing, Fakenhan Press, London, UK, 1975.

[30] P. 1. Garland, Ophthalmic Nursing, Faber and Faber, London, UK, 1995.

[31] World Health Assembly (WHA), "The resolution of world health assembly on the elimination of avoidable blindness," Community Eye Health, vol. 16, pp. 17-18, 2003.

[32] G. N. Dennis and D. Paul, "School vision screening programme in enugu, Nigeria: assessment of referral criteria for error of refraction," Nigerian Journal of Ophthalmology, pp. 34-40, 1997.

[33] P. F. Jacques, S. M. Moeller, S. E. Hankinson et al., "Weight status, abdominal adiposity, diabetes, and early age-related lens opacities," American Journal of Clinical Nutrition, vol. 78, no. 3, pp. 400-405, 2003.

[34] B. E. K. Klein, R. Klein, K. E. Lee, and S. C. Jensen, "Measures of obesity and age-related eye diseases," Ophthalmic Epidemiology, vol. 8, no. 4, pp. 251-262, 2001. 
[35] T. M. Kuang, S. Y. Tsai, W. M. Hsu, C. Y. Cheng, J. H. Liu, and P. Chou, "Body mass index and age-related cataract: the Shihpai eye study," Archives of Ophthalmology, vol. 123, no. 8, pp. 11091114, 2005.

[36] D. A. Schaumberg, W. G. Christen, S. E. Hankinson, and R. J. Glynn, "Body mass index and the incidence of visually significant age-related maculopathy in men," Archives of Ophthalmology, vol. 119, no. 9, pp. 1259-1265, 2001.

[37] J. M. Seddon, J. Cote, N. Davis, and B. Rosner, "Progression of age-related macular degeneration: association with body mass index, waist circumference, and waist-hip ratio," Archives of Ophthalmology, vol. 121, no. 6, pp. 785-792, 2003.

[38] H. A. van Leiden, J. M. Dekker, A. C. Moll et al., "Risk factors for incident retinopathy in a diabetic and nondiabetic population: the Hoorn study," Archives of Ophthalmology, vol. 121, no. 2, pp. 245-251, 2003.

[39] E. R. Schoenfeld, M. C. Leske, and S.-Y. Wu, "Recent epidemiologic studies on nutrition and cataract in India, Italy and the United States," Journal of the American College of Nutrition, vol. 12, no. 5, pp. 521-526, 1993.

[40] E. A. Zang and E. L. Wynder, "The association between body mass index and the relative frequencies of diseases in a sample of hospitalized patients," Nutrition and Cancer, vol. 21, no. 3, pp. 247-261, 1994.

[41] M. C. Leske, A. M. S. Connell, S. Y. Wu, L. G. Hyman, and A. P. Schachat, "Risk factors for open-angle glaucoma: the Barbados eye study," Archives of Ophthalmology, vol. 113, no. 7, pp. 918924, 1995.

[42] P. Gasser, D. Stümpfig, A. Schötzau, U. Ackermann-Liebrich, and J. Flammer, "Body mass index in glaucoma," Journal of Glaucoma, vol. 8, no. 1, pp. 8-11, 1999.

[43] H. Momeni-Moghaddam, J. Kundart, M. Ehsani, and A. AbdehKykha, "Body mass index and binocular vision skills," Saudi Journal of Ophthalmology, vol. 26, no. 3, pp. 331-334, 2012.

[44] M. O. Ozor, I. O. Ernest-Nwoke, and M. O. Oyakhire, "Association between health status and visual functioning: a community based study," International Journal of Community Research, vol. 3, no. 1, pp. 19-24, 2014.

[45] A. J. Lee, J. J. Wang, A. Kifley, and P. Mitchell, "Open-angle glaucoma and cardiovascular mortality: the blue mountains eye study," Ophthalmology, vol. 113, no. 7, pp. 1069-1076, 2006.

[46] S. Y. Wu, B. Nemesure, A. Hennis, A. P. Schachat, L. Hyman, and M. C. Leske, "Open-angle glaucoma and mortality: the Barbados eye studies," Archives of Ophthalmology, vol. 126, no. 3, pp. 365-370, 2008.

[47] B. C. Chauhan, F. S. Mikelberg, A. G. Balaszi, R. P. LeBlanc, M. R. Lesk, and G. E. Trope, "Canadian glaucoma study: 2. Risk factors for the progression of open-angle glaucoma," Archives of Ophthalmology, vol. 126, no. 8, pp. 1030-1036, 2008.

[48] J. Flammer, K. Konieczka, R. M. Bruno, A. Virdis, A. J. Flammer, and S. Taddei, "The eye and the heart," European Heart Journal, vol. 34, no. 17, pp. 1270-1278, 2013. 

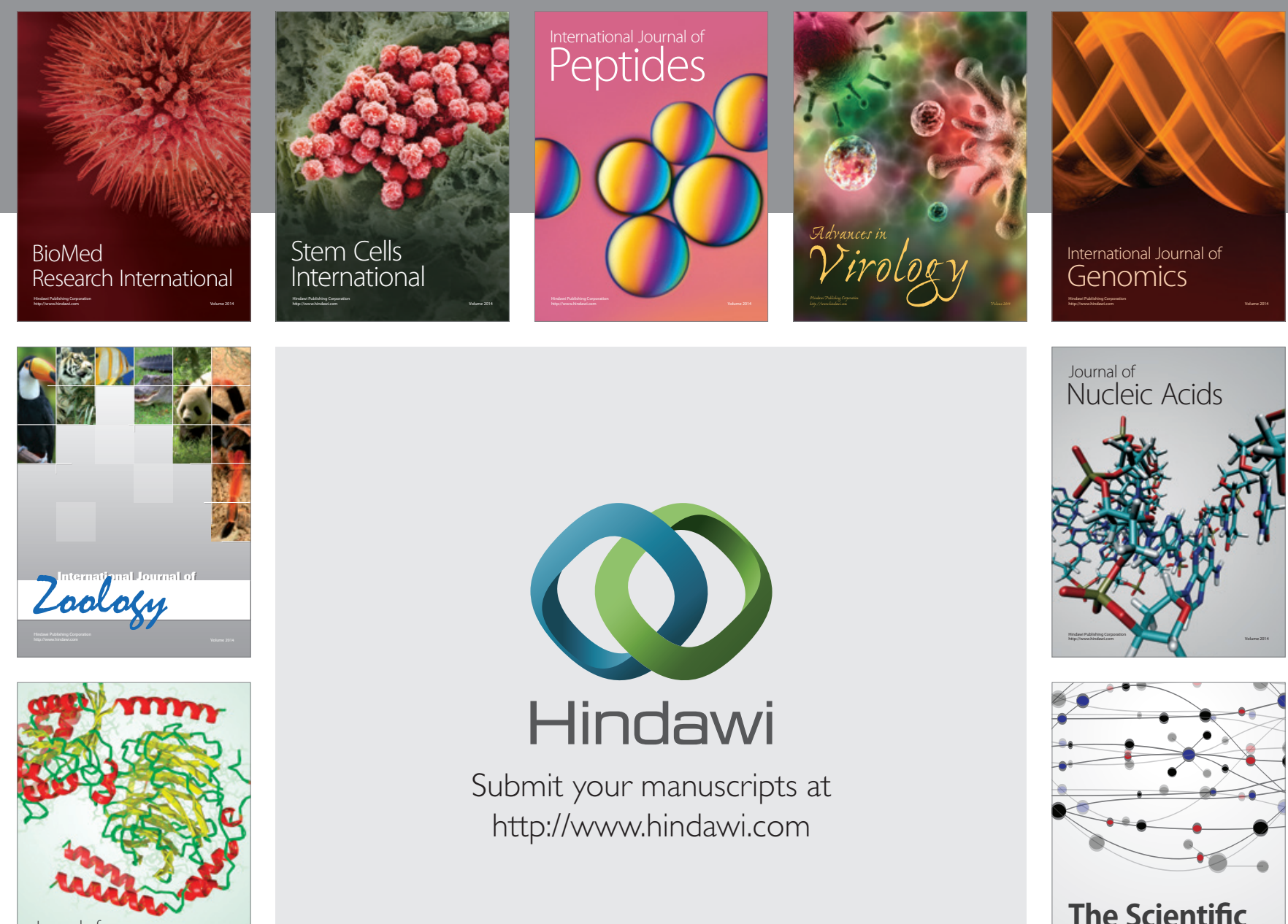

Submit your manuscripts at

http://www.hindawi.com

Journal of
Signal Transduction
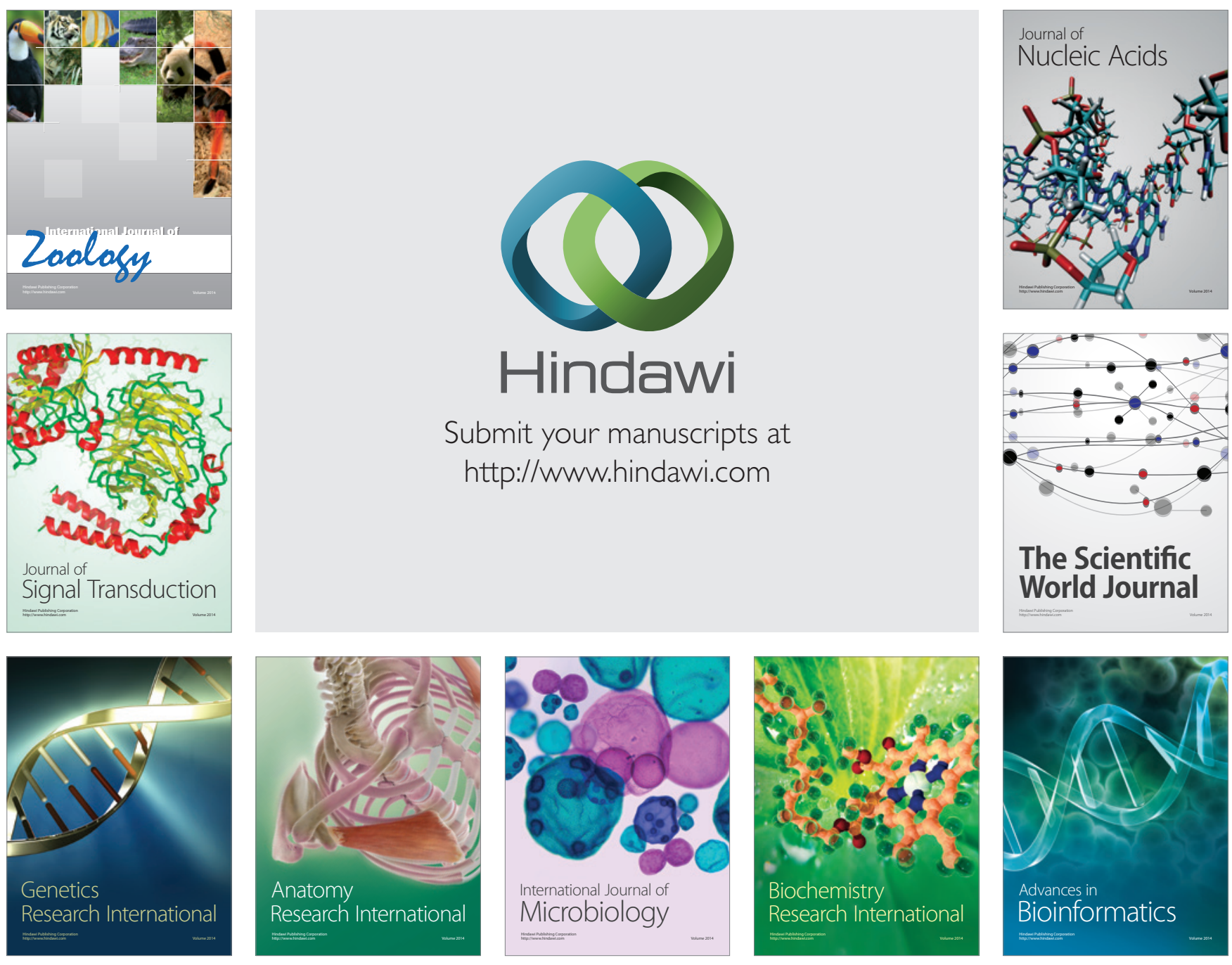

The Scientific World Journal
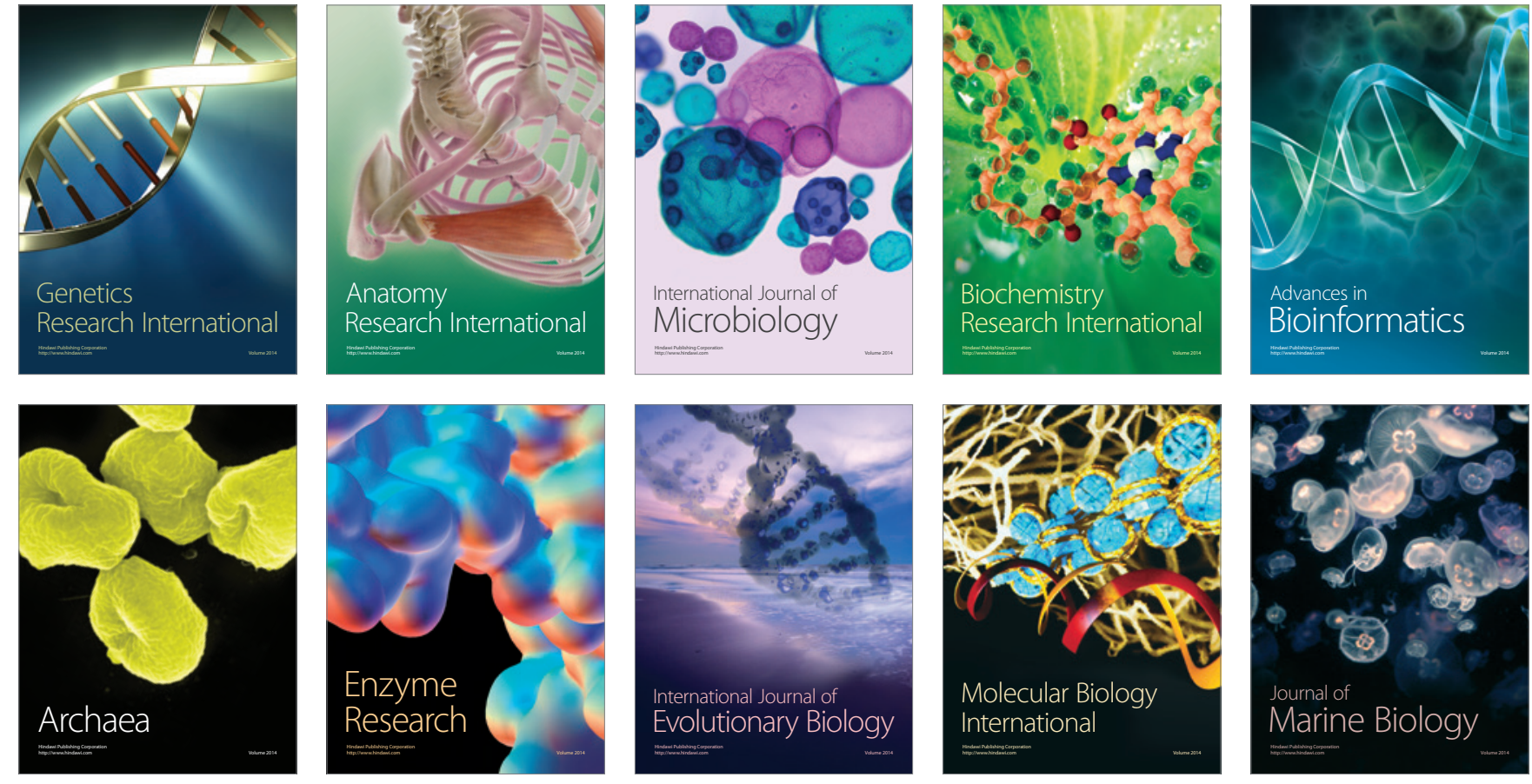